\title{
Are the native giant tortoises from the Seychelles really extinct? A genetic perspective based on mtDNA and microsatellite data
}

\author{
ERIC P. PALKOVACS,$*$ MONIQUE MARSCHNER,${ }^{*}$ CLAUDIO CIOFI,${ }^{*}+$ JUSTIN GERLACH $\ddagger$ and \\ ADALGISA CACCONE*+ \\ *Department of Ecology and Evolutionary Biology, Yale University, 165 Prospect Street, + Molecular Systematics and Conservation \\ Genetics Laboratory, Yale Institute for Biospheric Studies, 21 Sachem Street, New Haven, CT 06520, USA, łUniversity Museum of \\ Zoology Cambridge, Department of Zoology, Downing Street, Cambridge, CB2 EJ3, UK
}

\begin{abstract}
The extinction of the giant tortoises of the Seychelles Archipelago has long been suspected but is not beyond doubt. A recent morphological study of the giant tortoises of the western Indian Ocean concluded that specimens of two native Seychelles species survive in captivity today alongside giant tortoises of Aldabra, which are numerous in zoos as well as in the wild. This claim has been controversial because some of the morphological characters used to identify these species, several measures of carapace morphology, are reputed to be quite sensitive to captive conditions. Nonetheless, the potential survival of giant tortoise species previously thought extinct presents an exciting scenario for conservation. We used mitochondrial DNA sequences and nuclear microsatellites to examine the validity of the rediscovered species of Seychelles giant tortoises. Our results indicate that the morphotypes suspected to represent Seychelles species do not show levels of variation and genetic structuring consistent with long periods of reproductive isolation. We found no variation in the mitochondrial control region among 55 individuals examined and no genetic structuring in eight microsatellite loci, pointing to the survival of just a single lineage of Indian Ocean tortoises.
\end{abstract}

Keywords: Aldabra, Aldabrachelys, Dipsochelys, giant tortoise, microsatellites, mitochondrial control region, Seychelles

Received 5 August 2002; revision received 16 January 2003; accepted 30 January 2003

\section{Introduction}

Giant tortoises of the genus Dipsochelys (also known as Aldabrachelys or Geochelone gigantea) once existed on islands throughout the western Indian Ocean including Madagascar, the Comoros, Aldabra and the Seychelles. However, by 1840 they seemed to have been eliminated from all but one, the island of Aldabra. The extirpation of giant tortoises from these oceanic islands appears to have been the direct result of overexploitation by early European sailors and settlers (Stoddart et al. 1979). While most authorities have accepted the extinction of all non-Aldabran forms, some reports have suggested the presence of

Correspondence: Eric P. Palkovacs. Fax: + 1203 4327394; E-mail: eric.palkovacs@yale.edu tortoises of Seychelles origin held in captivity (Penny 1970; Bour 1982, 1984). These reports have typically been interpreted as the misidentification of Aldabran tortoises with morphological aberrations caused by inappropriate captive diets (Arnold 1979). However, Aldabran tortoises were introduced to the Seychelles while a few native specimens still survived (Bour 1984). Subsequent mixing between native tortoises and introduced tortoises may have obscured the ultimate fate of the Seychelles taxa.

In 1995, three captive tortoises (two alive and one dead) resembling those tortoises originally described from the Seychelles (Günther 1877; Bour 1982) were examined by Gerlach \& Canning (1998a,b). Although these tortoises could not be conclusively identified on the basis of external morphology, they inspired Gerlach \& Canning to undertake a taxonomic revision of all Dipsochelys giant tortoises. 


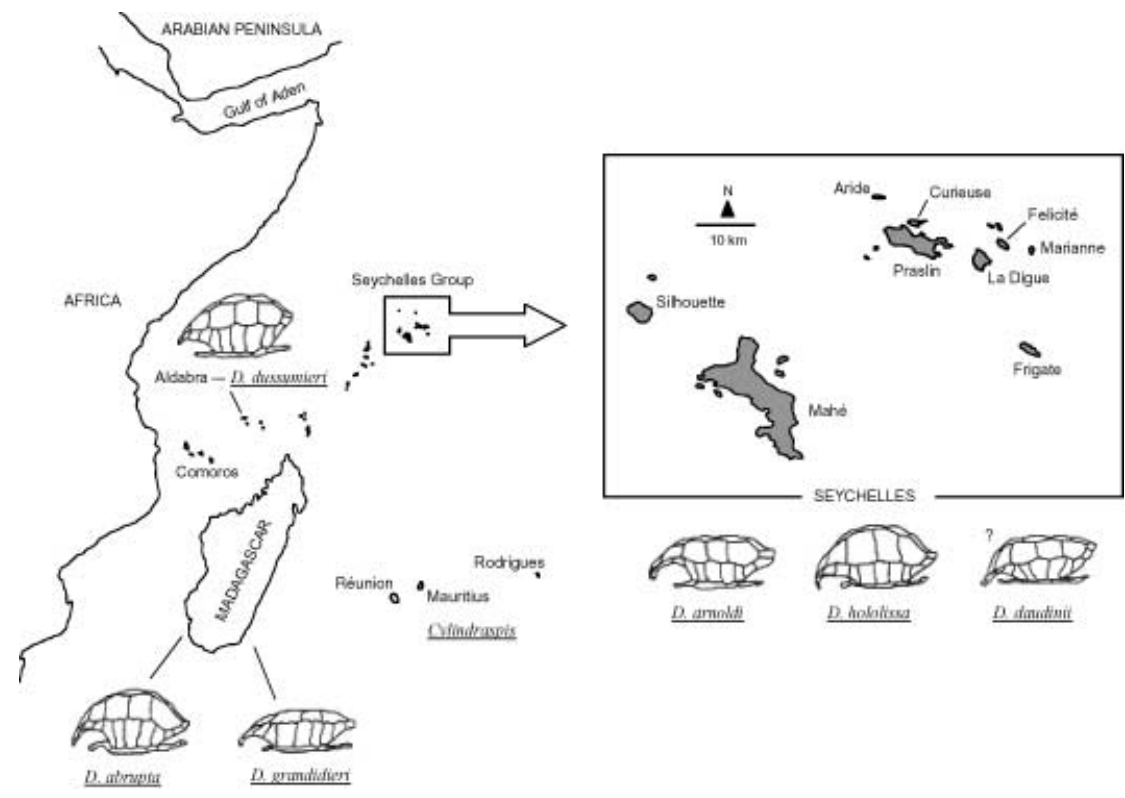

Fig. 1 Map of Indian Ocean islands where giant tortoises have existed, with carapace morphologies of Dipsochelys species depicted. Aldabra is the only island currently populated by native wild tortoises. Dipsochelys daudinii is hypothesized to be from the Seychelles, but this origin is uncertain. Cylindraspis is an extinct genus containing five species endemic to the Mascarene Islands of Réunion, Mauritius and Rodrigues.

Gerlach \& Canning (1998a) examined 84 skeletal and shell specimens of Dipsochelys and postulated six distinct species using primarily osteological and morphological characters: D. dussumieri from Aldabra, D. hololissa and D. arnoldi from the Seychelles, $D$. daudinii of ambiguous origin but possibly from the Seychelles, and D. abrupta and D. grandidieri from Madagascar (Fig. 1). As a result of incomplete remains, the tortoises of the Comoros have not been classified but have been suggested to be part of the Dipsochelys group (Bour 1994). Morphological examination of live specimens (Gerlach \& Canning 1998a) and a preliminary genetic analysis based on randomly amplified polymorphic DNA (RAPDs) (L. Noble, reported in Gerlach \& Canning 1998b) prompted Gerlach \& Canning (1998a,b) to suggest that, in fact, two of the Seychelles species, $D$. hololissa and D. arnoldi, are not extinct forms, but are alive in captivity today. On the basis of morphological differences, a captive breeding programme was initiated.

To address the survival of Seychelles tortoises, we examined the genetic distinctness of the surviving morphotypes reported by Gerlach \& Canning (1998a,b). Using sequence data from the mitochondrial $12 \mathrm{~S}$ and $16 \mathrm{~S}$ ribosomal RNA (rRNA) and cytochrome $b$ (cyt $b$ ) genes, Palkovacs et al. (2002) found no variability within or among captive tortoises morphologically assigned to one of the three species described by Gerlach \& Canning (1998a). Arnold et al. (2003) analysed cyt $b$ sequences from modern and museum skin Dipsochelys specimens and also found extremely low variability. In this study, we increased the sample size, including samples taken from wild tortoises from Aldabra, and examined the more rapidly evolving control region of the mitochondrial DNA (mtDNA) as well as eight nuclear microsatellite loci.

\section{Materials and methods}

\section{Species assignments}

Thirty-two captive tortoises were examined and assigned to one of three species, Dipsochelys arnoldi, D. dussumieri, or D. hololissa, based on carapace morphology as described by Gerlach \& Canning (1998a) (Table 1). In short, D. arnoldi has an elongate, saddle-backed shell, D. dussumieri possesses an evenly domed carapace, and D. hololissa has a domed yet broad and dorsally flattened carapace (see carapace morphology in Fig. 1). Ten wild tortoises from Aldabra were classified as D. dussumieri. Thirteen individuals were not examined morphologically and, thus, were not assigned to a taxon.

\section{Genetic analysis}

We analysed a total of 55 blood samples, including 25 D. dussumieri, 10 D. hololissa, seven D. arnoldi and 13 (morphologically) unexamined, thus unidentified, individuals. Total genomic DNA was isolated from blood samples using the Easy DNA kit (Invitrogen). Primers for polymerase chain reaction (PCR) amplification of mtDNA sequences including the control region were initially designed from the transfer RNA (tRNA) threonine and phenylalanine genes of the Painted turtle (Chrysemys picta) mitochondrial genome (Mindell et al. 1999). The use of primer Thr-L15569 (5'-CATTGGTCTTGTAAACCAAAGACTG-3') in combination with primer Phe-H26 (5'-TACCCATCTTGGCAACTTCAGTGCC-3') allowed the amplification of a mtDNA fragment, which includes the complete sequence of the tRNA proline gene and the control 
Table 1 Sources of samples. Genotypic assignment is reported for those taxa for which the probability of belonging for the individual was higher than $1 \%$. The taxon for which the probability of belonging was the highest is reported first

\begin{tabular}{|c|c|c|c|c|}
\hline Local ID & ISIS* & Specimen origin & $\begin{array}{l}\text { Morphological } \\
\text { species assignment }\end{array}$ & Genotypic assignment \\
\hline Stan & & NPTS Silhouette, Seychelles & D. arnoldi & D. dussumieri, hololissa \\
\hline Clio & & NPTS Silhouette, Seychelles & D. arnoldi & D. dussumieri, hololissa \\
\hline Hector & & NPTS Silhouette, Seychelles & D. arnoldi & D. arnoldi, hololissa, dussumieri \\
\hline Betty & & NPTS Silhouette, Seychelles & D. arnoldi & D. arnoldi, hololissa \\
\hline Adrian & & NPTS Silhouette, Seychelles & D. arnoldi & D. hololissa, arnoldi, dussumieri \\
\hline CR82 & $\mathrm{T} 1075$ & Sedgwick County Zoo, Kansas, USA & D. arnoldi & D. dussumieri, hololissa, arnoldi \\
\hline 6137 & $\mathrm{~T} 1162$ & Sedgwick County Zoo, Kansas, USA & D. arnoldi & D. dussumieri \\
\hline H00086 & T1109 & Miami Metrozoo, Florida, USA & D. dussumieri & D. hololissa, dussumieri, arnoldi \\
\hline H00086 & $\mathrm{T} 1110$ & Miami Metrozoo, Florida, USA & D. dussumieri & D. dussumieri, hololissa, arnoldi \\
\hline P1 & & Wild, Aldabra & D. dussumieri & D. hololissa, arnoldi, dussumieri \\
\hline P2 & & Wild, Aldabra & D. dussumieri & D. dussumieri \\
\hline P3 & & Wild, Aldabra & D. dussumieri & D. dussumieri, hololissa, arnoldi \\
\hline $\mathrm{P} 4$ & & Wild, Aldabra & D. dussumieri & D. dussumieri, hololissa \\
\hline GT1 & & Wild, Aldabra & D. dussumieri & D. dussumieri, arnoldi, hololissa \\
\hline GT2 & & Wild, Aldabra & D. dussumieri & D. dussumieri \\
\hline GT3 & & Wild, Aldabra & D. dussumieri & D. arnoldi, dussumieri, hololissa \\
\hline GT4 & & Wild, Aldabra & D. dussumieri & D. dussumieri, arnoldi, hololissa \\
\hline GT5 & & Wild, Aldabra & D. dussumieri & not assigned \\
\hline Biscuit & & Wild, Aldabra & D. dussumieri & D. dussumieri, hololissa \\
\hline B & & IDC Silhouette, Seychelles & D. dussumieri & D. dussumieri, hololissa \\
\hline C & & IDC Silhouette, Seychelles & D. dussumieri & D. hololissa, dussumieri \\
\hline G & & IDC Silhouette, Seychelles & D. dussumieri & D. hololissa, arnoldi, dussumieri \\
\hline $\mathrm{T}$ & & IDC Silhouette, Seychelles & D. dussumieri & D. dussumieri, arnoldi, hololissa \\
\hline 900194 & $\mathrm{~T} 1395$ & Honolulu Zoo, Hawaii, USA & D. dussumieri & D. dussumieri, arnoldi, hololissa \\
\hline 900195 & T1396 & Honolulu Zoo, Hawaii, USA & D. dussumieri & not assigned \\
\hline 900196 & $\mathrm{~T} 1397$ & Honolulu Zoo, Hawaii, USA & D. dussumieri & D. dussumieri, hololissa, arnoldi \\
\hline 900197 & $\mathrm{~T} 1398$ & Honolulu Zoo, Hawaii, USA & D. dussumieri & D. dussumieri, hololissa, arnoldi \\
\hline 3307 & $\mathrm{~T} 1304$ & Phoenix Zoo, Arizona, USA & D. dussumieri & D. arnoldi, dussumieri, hololissa \\
\hline 318 & $\mathrm{~T} 1171$ & Phoenix Zoo, Arizona, USA & D. dussumieri & D. dussumieri, hololissa, arnoldi \\
\hline 7620 & $\mathrm{~T} 1050$ & Phoenix Zoo, Arizona, USA & D. dussumieri & D. hololissa, dussumieri, arnoldi \\
\hline 11487 & $\mathrm{~T} 1331$ & Tulsa Zoo, Oklahoma, USA & D. dussumieri & D. dussumieri, arnoldi, hololissa \\
\hline 11006 & $\mathrm{~T} 1368$ & Tulsa Zoo, Oklahoma, USA & D. dussumieri & D. hololissa, arnoldi, dussumieri \\
\hline 1200 & & Bristol Zoo, England, UK & D. hololissa & not assigned \\
\hline Adam & & NPTS Silhouette, Seychelles & D. hololissa & D. hololissa, arnoldi, dussumieri \\
\hline Eve & & NPTS Silhouette, Seychelles & D. hololissa & D. dussumieri, hololissa, arnoldi \\
\hline Christopher & & NPTS Silhouette, Seychelles & D. hololissa & D. dussumieri, hololissa \\
\hline Phoenix & & NPTS Silhouette, Seychelles & D. hololissa & D. dussumieri, arnoldi \\
\hline 2277 & $\mathrm{~T} 1038$ & Detroit Zoo, Michigan, USA & D. hololissa & D. hololissa, dussumieri, arnoldi \\
\hline 2278 & $\mathrm{~T} 1039$ & Detroit Zoo, Michigan, USA & D. hololissa & not assigned \\
\hline 900191 & $\mathrm{~T} 1392$ & Honolulu Zoo, Hawaii, USA & D. hololissa & D. arnoldi, dussumieri, hololissa \\
\hline 900193 & $\mathrm{~T} 1394$ & Honolulu Zoo, Hawaii, USA & D. hololissa & D. hololissa, dussumieri, arnoldi \\
\hline 6138 & $\mathrm{~T} 1107$ & Sedgwick County Zoo, Kansas, USA & D. hololissa & D. dussumieri, arnoldi \\
\hline 931321 & & Melbourne Zoo, Victoria, Australia & Unidentified & \\
\hline 750020 & & Melbourne Zoo, Victoria, Australia & Unidentified & \\
\hline 650005 & & Melbourne Zoo, Victoria, Australia & Unidentified & \\
\hline 950210 & & Melbourne Zoo, Victoria, Australia & Unidentified & \\
\hline 750019 & & Melbourne Zoo, Victoria, Australia & Unidentified & \\
\hline 300008 & $\mathrm{~T} 1028$ & Loiusville Zoo, Kentucky, USA & Unidentified & \\
\hline 300447 & $\mathrm{~T} 1383$ & Loiusville Zoo, Kentucky, USA & Unidentified & \\
\hline 300494 & & Loiusville Zoo, Kentucky, USA & Unidentified & \\
\hline 300419 & $\mathrm{~T} 1158$ & Loiusville Zoo, Kentucky, USA & Unidentified & \\
\hline 300446 & $\mathrm{~T} 1384$ & Loiusville Zoo, Kentucky, USA & Unidentified & \\
\hline 300493 & $\mathrm{~T} 1404$ & Loiusville Zoo, Kentucky, USA & Unidentified & \\
\hline 3308 & $\mathrm{~T} 1305$ & Phoenix Zoo, Arizona, USA & Unidentified & \\
\hline 10506 & $\mathrm{~T} 1149$ & Tulsa Zoo, Oklahoma, USA & Unidentified & \\
\hline
\end{tabular}

*The International Species Information System (ISIS) number is provided when available. 
region. After sequencing the entire region in two Dipsochelys individuals, we designed primers specific to this genus. Primer ALD-DLAFor (5'-AGACTCAAACCCTCATCTCCGG- $3^{\prime}$ ) is located inside the tRNA proline gene, 37 base pairs (bp) from the start of the control region, and primer ALD-DLBRev (5'-ACGATGTGCAGTGGGAGTGGTTG-3') is $14 \mathrm{bp}$ from the end of the control region. This primer pair amplified a 915-bp fragment in all the Dipsochelys individuals studied.

PCR amplification was performed in a Stratagene Robocylcer Gradient 96 Temperature Cycler, using $50 \mu$ L reactions containing $1 \mu \mathrm{L}$ genomic DNA, $10 \mathrm{~mm}$ Tris- $\mathrm{HCl}$ ( $\mathrm{pH}$ 8.3), $50 \mathrm{~mm} \mathrm{KCl}, 1.5 \mathrm{~mm} \mathrm{MgCl}_{2}, 0.8 \mathrm{~mm}$ DNTPs, $0.4 \mu \mathrm{m}$ of each primer and 1.5 units Amplitaq (Perkin-Elmer). Each PCR run consisted of an initial 2 min and $15 \mathrm{~s}$ denaturation step $\left(94^{\circ} \mathrm{C}\right)$, followed by 35 cycles of $1 \mathrm{~min}$ and $15 \mathrm{~s}$ denaturation at $94^{\circ} \mathrm{C}, 1 \mathrm{~min}$ and $15 \mathrm{~s}$ annealing at $57^{\circ} \mathrm{C}$, and extension for $2 \mathrm{~min}$ and $15 \mathrm{~s}$ at $72^{\circ} \mathrm{C}$. The last cycle was followed by a 5 -min incubation step at $72{ }^{\circ} \mathrm{C}$. PCR products were checked for expected size by electrophoresis of one-tenth of the product on $1 \%$ agarose gels stained with ethidium bromide. PCR fragments were cleaned using the Geneclean III kit (Bio 101). A negative control was run with each round of PCR.

Fragments were sequenced using an ABI Prism 377 automated DNA sequencer with BIGDYE TERMINATOR CYCLE SEQUENCING v2.0. In addition to the primers ALDDLAFor and ALD-DLBRev, we used two internal primers for sequencing: Ald-DL1FR (5'-GATCTATTCTGGCCTCTGG-3') and Ald-DL2Rev (5'-TAAAAGCGCAATATGCCAGG-3'). PCR fragments were sequenced in both directions to promote sequence accuracy. Mitochondrial DNA sequences were edited using SEQUENCHER 5.0 (Gene Codes Corporation) and deposited in GenBank (accession number AY210410).

Microsatellite analysis was performed using PCR primers designed for the Galápagos tortoise (Geochelone nigra or Geochelone elephantopus, see Zug 1997). We obtained clear amplification at eight loci. Primer sequences and PCR conditions for six loci (GAL50, GAL73, GAL94, GAL100, GAL136 and GAL263) are reported in Ciofi et al. (2002). Locus GAL85 was amplified using the primer pair GAL85F (5'-TGTGGGGCATGGAAGGGCC-3') and GAL85R (5'-CACCAAGAGAGGAAAATAATGCTGGG-3') with an annealing temperature of $62{ }^{\circ} \mathrm{C}$. Locus GAL247 was amplified using the primers GAL247F (5'-ATTAACTGATTTGAGCAGTCATCCA-3') and GAL247R (5'TGCTGTGAATAGTAACTGAGC-3') with an annealing temperature of $57^{\circ} \mathrm{C}$. Other PCR conditions for these two loci were as in Ciofi et al. (2002). PCR products were separated by electrophoresis using an ABI 373A DNA sequencer. Allele types on different gels were assigned using standard size markers. Allele sizes and frequencies are reported in Appendix 1.

\section{Statistical analysis}

We tested for linkage disequilibrium using the algorithm developed by Black \& Krafsur (1985). Overall allele differentiation at microsatellite loci was assessed by an exact probability test using the Markov chain method of Raymond \& Rousset (1995a). Both tests were performed in GENEPOP 3.3 (Raymond \& Rousset 1995b). Pairwise differences among named taxa were determined using the parameter $F_{\mathrm{ST}}$ (Wright 1965). Calculation of $F_{\mathrm{ST}}$ was based on the algorithm $\theta$ of Weir \& Cockerham (1984). Statistical significance of $\theta$ was assessed using GENETIX 4.01 (Belkhir et al. 2000). Assignment of individuals to named taxa (morphological species) was determined using a likelihoodbased, Bayesian technique implemented in GENECLAss (Cornuet et al. 1999). The test assigned tortoises to the taxon where the likelihood of their genotype was the highest. A measure of confidence that a tortoise truly belonged to a given taxon was obtained by comparing the likelihood of each individual genotype to the distribution of the likelihoods of 10000 randomly generated genotypes. Genotypes with likelihoods $<1 \%$ of belonging to any of the morphological species were not assigned. In addition, we constructed pairwise comparison diagrams and, for each tortoise, plotted the log-transformed likelihood of belonging to a taxon (see Waser \& Strobeck 1998).

The proposed Dipsochelys taxonomy was also investigated using the Bayesian model-based method of Pritchard et al. (2000) implemented in STRUCTURE. The program clusters individuals that are genetically similar and estimates the most appropriate number $(K)$ of clusters (taxa) needed to interpret the observed genotypes. The value of $K$ with the highest posterior probability was identified using 50000 Markov Chain Monte Carlo repetitions and a burnin period of 50000 iterations.

\section{Results}

The nucleotide composition of the control region of Dipsochelys (65\% A + T) is very similar to that reported for the same region in Galápagos tortoises (Caccone et al. 2002) and in other vertebrates (Zhu et al. 1994; Gemmel et al. 1996; Sbisá et al. 1997; Mindel et al. 1999). Quite surprisingly, all 55 Dipsochelys individuals examined had an identical haplotype regardless of their a priori morphological classification.

Out of 10 microsatellites initially tried, eight amplified consistently in Dipsochelys. This is a testament to the conserved nature of the flanking regions on which the microsatellite primers were designed and corroborates previous studies in marine turtles (FitzSimmons et al. 1995) and fish (Rico et al. 1996; Zardoya et al. 1996) that found successful amplification across distantly related taxa. Mean number of alleles per microsatellite locus was $2.3 \pm 0.8$, with a range 
Table 2 Characteristics of eight microsatellite loci used in Dipsochelys tortoises

\begin{tabular}{lllc}
\hline Locus & $\begin{array}{l}\text { Cloned } \\
\text { repeat }\end{array}$ & $\begin{array}{l}\text { No. of } \\
\text { alleles }\end{array}$ & $\begin{array}{l}\text { Allele } \\
\text { size (bp) }\end{array}$ \\
\hline GAL50 & CA(24) & 4 & $105-139$ \\
GAL73 & CA(24) & 2 & $84-86$ \\
GAL85 & CA(22) & 3 & $81-91$ \\
GAL94 & CA(18) & 5 & $101-113$ \\
GAL100 & CA(26) & 3 & $75-89$ \\
GAL136 & CA(20) & 8 & $85-163$ \\
GAL247 & CA(39) & 3 & $69-93$ \\
GAL263 & CA(17) & 8 & $95-119$ \\
\hline
\end{tabular}

of two to eight alleles (see Table 2). There was no evidence of non-random association of genotypes $(P>0.05)$ in any of the 28 tests for linkage disequilibrium performed for each locus pair across taxa.

There were no significant differences in allelic diversity (mean number of alleles across loci) among $D$. arnoldi, $D$. dussumieri, and D. hololissa (ANova; $F=0.743, P=0.488$ ). Comparison of the allele frequency distribution also revealed no differentiation among the named taxa (Fisher's exact test; $P=0.175)$. Similarly, multilocus values of $F_{\mathrm{ST}}$ did not resolve any significant pattern of differentiation $\left(F_{\mathrm{ST}}=0.015 ; P>0.05\right)$. The results of the assignment test also found little evidence of genetic structuring that could corroborate the proposed taxonomic subdivision. Genotypic assignments in agreement with morphology would be revealed in the top panel of Fig. 2, for instance, if the specimens morphologically assigned to $D$. dussumieri (open circles) were clustered in the top left corner of the plot, indicating a high probability of belonging to the $D$. dussumieri morphotype and a low probability of belonging to the $D$. arnoldi morphotype. The lack of clustering in the top left or bottom right corners of any of the probability of assignment plots in Fig. 2 shows that the genotypic assignments fail to support the morphological groupings. Table 1 also reveals general inconsistency between the morphological and genotypic species assignments. Just 5\% of specimens were genetically assigned to only one taxon in agreement with their morphological assignment, and only $48 \%$ had their primary genotypic assignment (first listed in Table 1) agree with their morphological assignment. Sixty per cent could be assigned to all three morphological groups, while $10 \%$ could not be assigned to any. Dipsochelys dussumieri had the highest concordance between morphological and primary genotypic assignment at $60 \%$, while agreement for D. arnoldi and D. hololissa was $29 \%$ and $30 \%$, respectively.

We also employed our microsatellite data to infer population structure using the approach described in Pritchard et al. (2000). We estimated $P(X \mid K)$ and the posterior probability $P(K \mid X)$ for a number of possible clusters varying

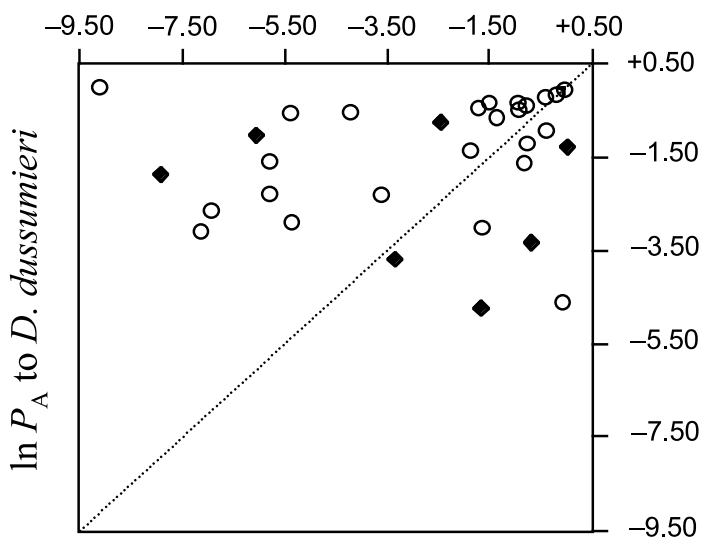

$\ln P_{\mathrm{A}}$ to $D$. arnoldi

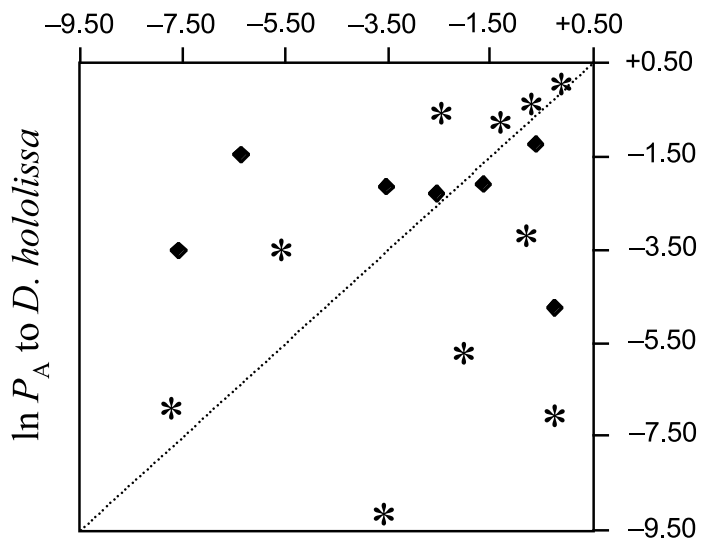

$\ln P_{\mathrm{A}}$ to $D$. arnoldi

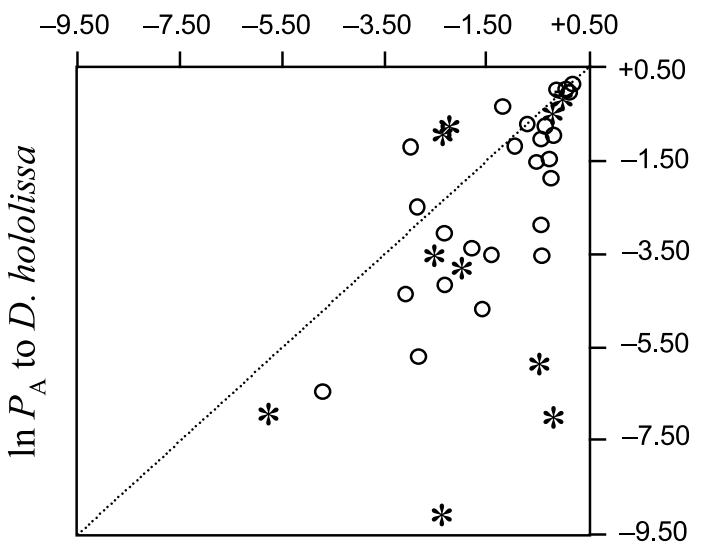

$\ln P_{\mathrm{A}}$ to $D$. dussumieri

D. arnoldi $(\bullet)$ D. dussumieri (०) D. hololissa (*)

Fig. 2 Diagrams of natural logarithmic values of probabilities of assignment $\left(P_{\mathrm{A}}\right)$ to three named Dipsochelys taxa. For each tortoise multilocus genotype, log-transformed likelihood values of belonging to the taxa considered in each pairwise comparison diagram are reported on the $x$ and $y$ coordinates, respectively. The probability of genetically assigning a tortoise to its original morphotype increases as its multilocus genotype is plotted closer to either the top left corner (species on $y$ axis) or bottom right corner (species on $x$ axis) of each plot. 
Table 3 Estimates of the logarithm of the probability of the data and of the posterior probability of $K$ for a number of clusters (taxa) varying from $K=1$ to $K=5$

\begin{tabular}{lll}
\hline$K$ & $\ln P(X \mid K)$ & $P(K \mid X)$ \\
\hline 1 & -645.5 & 0.999 \\
2 & -681.8 & 0.268 \\
3 & -696.9 & 0.084 \\
4 & -686.8 & 0.151 \\
5 & -688.6 & 0.109 \\
\hline
\end{tabular}

from $K=1$ to $K=5$. From the posterior probabilities, it is evident that the most likely number of clusters to explain our data is $K=1$ (Table 3), indicating no substructuring in our sample. The results of the above analyses provide strong evidence for a lack of genotypic differentiation among the Dipsochelys morphotypes examined.

\section{Discussion}

The combination of genetic and phenotypic analyses is a powerful approach for designating species boundaries and evolutionarily significant units (ESUs) for taxonomy and conservation. While neutral genetic variation reveals historical isolation, genetically based phenotypic variation may reflect ecological adaptation (Crandall et al. 2000). Thus, we examined neutral genetic variation in Indian Ocean giant tortoises in light of morphological differences to determine whether previously identified morphotypes represent surviving species of native Seychelles tortoises. The results of our analysis of quickly evolving mitochondrial and nuclear markers conflict with the morphological analysis (Gerlach \& Canning 1998a) and the preliminary analysis of RAPD data (L. Noble, reported in Gerlach \& Canning 1998b) that divide captive Dipsochelys individuals into three distinguishable groups, designated as three distinct species by Gerlach \& Canning $(1998 \mathrm{a}, \mathrm{b})$. Our data provide no evidence for genetic differentiation between these morphotypes, indicating that there is just a single surviving lineage of Indian Ocean giant tortoises. In addition, our finding of no variation among 55 Dipsochelys control region sequences is unexpected for this typically highly variable region. We contrast our results with those from genetic studies of other insular giant tortoise radiations, evaluate several possible explanations for the existence of a single surviving lineage, discuss the implications of a previous genetic analysis based on RAPD data, and examine why the control region may be invariant in this lineage.

\section{Other giant tortoise radiations}

The lack of genetic structuring among the Dipsochelys morphological groups examined here contrasts sharply with patterns of genetic variation found in other giant tortoise island radiations. Detailed studies of Galápagos tortoises using a variety of mitochondrial and nuclear markers have revealed high levels of inter- and intra-island population structuring. Tortoises colonized the Galápagos Archipelago from South America about 3 million years ago (Caccone et al. 1999, 2002), and 11 of the original 15 named Galápagos subspecies survive today (MacFarland et al. 1974; Pritchard 1996). Six are endemic to individual islands, and five occur on each of the five volcanoes on Isabela, the largest island in the archipelago. In a sample of 161 Galápagos tortoises representing all the currently recognized taxa, Caccone et al. (2002) found $85 \mathrm{mtDNA}$ haplotypes. Recent studies on the mitochondrial control region and microsatellites in Galápagos tortoises have revealed variability and genetic structuring among islands and between some populations inhabiting the same island. For the control region, sequence divergence between Galápagos tortoise populations was found to be as high as $20 \%$, while within-population estimates ranged from 0 to 6\% (Caccone et al. 2002; Beheregaray et al. 2003). Analysis of 10 microsatellite loci by Ciofi et al. (2002) found 12-37 alleles per locus and revealed significant population structuring for all loci and populations examined, as revealed by global $F_{\mathrm{ST}}$ analysis. Likewise, all pairwise comparisons between islands were significant, as were differences between distinct populations sharing the islands of Santa Cruz and Isabela.

Giant tortoises once inhabiting the Mascarene Islands of Réunion, Mauritius and Rodrigues, 700-1400 km east of Madagascar in the Indian Ocean, have also been the subjects of molecular phylogenetic study. Like the AldabraSeychelles and Galápagos tortoises, the Mascarene tortoises (Cylindraspis) were heavily exploited during early European settlement. As a result, populations on all three islands were driven extinct around 1800 (Stoddart et al. 1979). Austin \& Arnold (2001) examined a sequence of $428 \mathrm{bp}$ from the tRNA glutamine and cyt $b$ genes from subfossils and museum specimens of the five extinct species of Mascarene tortoises. Their analysis revealed 1.98-16.95\% sequence divergence among species, a level of variation sufficient to infer a pattern of island colonization for this group. These results for Galápagos and Mascarene tortoises contrast with our data for three hypothesized Aldabra-Seychelles species, which show no variation in the mtDNA 12S, 16S, or cyt $b$ genes (Palkovacs et al. 2002), no variation in the fast evolving mitochondrial control region, and no significant structuring for eight nuclear microsatellite loci.

\section{Explanations for a single surviving lineage}

The lack of variation and structuring in Dipsochelys indicates the survival of a single lineage. There are several 
possible explanations for this finding: (i) the native Seychelles species are extinct and all surviving Dipsochelys are from Aldabra; (ii) there never was more than one species of Dipsochelys; or (iii) hybridization between Aldabran and Seychelles tortoises has generated the pattern of morphological and genetic variation observed. These possible explanations are discussed in detail below.

First, our results could confirm the extinction of all nonAldabran Indian Ocean giant tortoises, meaning that all tortoises in captivity today, including those examined by Gerlach \& Canning (1998a,b), are originally of Aldabran stock. This interpretation is consistent with some previous studies of historical records (Stoddart et al. 1979) and Indian Ocean tortoise systematics (Arnold 1979). Austin et al. (2003) examined museum skin material reported to be from native Seychelles tortoises. They found that these specimens share a common cyt $b$ haplotype with living Aldabra tortoises, suggesting that these 'Seychelles' tortoises may actually be of Aldabran origin, and raise the possibility that the native Seychelles species may have been extinct before having been collected. The rapid extermination of tortoises from islands throughout the Indian Ocean (see Stoddardt et al. 1979) and the extensive exportation of tortoises from Aldabra (see Austin et al. 2003) make this explanation plausible.

If all the tortoises in our sample are of Aldabran descent, then what is a likely explanation for the morphological variation described by Gerlach \& Canning (1998a)? It has been suggested that carapace morphology is sensitive to environmental conditions and that captivity can result in aberrant morphologies. However, the pattern of morphological variation described for these groups involves complex changes in shell morphology and osteology that may not owe their origins to simple dietary abnormalities. Since we do not have data to address the degree of phenotypic plasticity in the morphological traits in question, we cannot provide an adequate explanation for this variation here, but one of us (J.G.) is in the process of examining the effects of captive conditions on phenotype.

An alternative interpretation of our results is that only one lineage of giant tortoise from Aldabra and the Seychelles ever existed. This could be possible if there was substantial gene flow between Aldabra and the Seychelles islands to prevent genetic divergence between these populations. However, significant differentiation among tortoise populations on the Galápagos and Mascarene archipelagos (described above) suggests that regular gene flow between oceanic islands is extremely unlikely. Another possibility is if the separation between the Aldabra and Seychelles populations was very recent. If such a recent split did happen, and if Gerlach and Canning's morphological interpretations are correct, an extremely rapid rate of morphological divergence among populations would have occurred in this giant tortoise lineage.
Finally, our findings might indicate hybridization between Aldabran imports and native Seychelles species. If imported Aldabran females interbred with the few remaining native Seychelles tortoises, Seychelles mtDNA haplotypes might have been swamped out and hybrid individuals might have intermediate or Seychelles-like morphologies. This might explain the single mtDNA haplotype and morphological differences we observed. If this were the case, however, we would expect to find microsatellite alleles in suspected hybrids that do not occur in tortoises of Aldabran origin (e.g. Roy et al. 1994), and such alleles would result in population structuring. No structuring was detected, so it is doubtful that hybridization has played an important role.

Of the above hypotheses, the extinction of Seychelles tortoises is the most likely interpretation of our results. However, the alternative hypotheses cannot be completely discounted until more information, such as genetic data from Seychelles subfossils, is available. If subfossils were to show significant differentiation from the living Dipsochelys specimens examined here and from the museum skins examined by Austin et al. (2003), it would show without doubt that at least one species of Seychelles tortoise, distinct from the tortoises of Aldabra, existed and is now extinct. However, if subfossils were not to show significant differentiation from living Aldabra tortoises, it would indicate that only one species of Aldabra-Seychelles tortoise ever existed.

\section{Conflict with RAPDs}

The RAPD data presented in Gerlach \& Canning (1998b) support the genetic distinctiveness of the morphological groupings, while the control region sequences and microsatellite data presented here do not. This discrepancy may be the result of the preliminary nature of the RAPD data or of the shortcomings of the RAPD technique. The RAPD technique is of limited utility because of its sensitivity to DNA template concentrations, its generally recognized lack of reproducibility, and the relatively high likelihood of nonhomology among co-migrating fragments (see Palumbi 1996; Ritland \& Ritland 2000). Despite these limitations, it is intriguing that the RAPDs appear to recover the same groupings as the morphological analysis. Thus, it is possible that some of the RAPD markers are linked to regions of the genome responsible for the morphological differences observed. There is evidence of correlations among the morphological traits in question (Gerlach 1999, 2003). Therefore, a relatively simple genetic change may have resulted in the suite of morphological differences observed. However, the neutral markers examined here suggest that these morphological differences, if genetically based, did not evolve during a long period of reproductive isolation. Nonetheless, if the morphological 
differences reported by Gerlach \& Canning (1998a) were conclusively shown to have a genetic basis, these morphotypes would warrant designation as ESUs on the principle of ecological nonexchangability as described in Crandall et al. (2000) despite their lack of differentiation at neutral genetic sites.

\section{Lack of control region variation}

The absence of genetic variation in $915 \mathrm{bp}$ of the most rapidly evolving fragment of the mtDNA molecule is an unusual finding, but is unlikely to be an artefact of either our laboratory procedure or our sampling strategy. We received and processed samples at different times and ran negative controls with every round of PCR so it is implausible that laboratory reagents were contaminated by a single DNA sample. Moreover, contamination by a single DNA sample would have resulted in identical genotypes at microsatellite loci, which was not observed. Multiple samples were re-extracted and reanalysed to confirm our findings. Identical haplotypes would also result if we had sampled only closely related individuals from a single maternal line. Although improbable, this scenario cannot be completely ruled out for some captive animals in our sample, because data on their origins are, in some cases, incomplete. However, our sample includes captive animals whose origin can be traced back to Aldabra, and tortoises from the wild Aldabran population. Therefore our total sample is very unlikely to be comprised of all closely related individuals.

If we consider the extinction of the native Seychelles tortoises to be the most likely scenario given our data, an historical explanation involving colonization and demography of Aldabra tortoises is likely to account for the lack of mitochondrial diversity observed. Other authors who have found low levels of control region variation in various organisms including birds (Baker et al. 1994), primates (Lawler et al. 1995) and turtles (Walker et al. 1998) have favoured explanations based on historical bottlenecks or recent colonization events, and the history of the Aldabra tortoise population suggests that these factors may be responsible here as well.

Aldabra tortoises have a history marked by regular extinctions, subsequent colonizations, and, in historical times, a dramatic bottleneck. Aldabra, a low coralline island, is sensitive to sea-level changes and has fluctuated dramatically in land area since the first record of giant tortoises on that island (Taylor et al. 1979). Two complete marine inundations, the most recent of which occurred just 125000 years ago, eliminated giant tortoises from Aldabra, but following each re-emergence the island was recolonized by tortoises whose fragmentary fossil remains are indistinguishable from those that survive there today (Arnold 1979). After sea levels fell and terrestrial vegetation had an opportunity to re-establish, perhaps $80000-$ 100000 years ago (Arnold 1979), it is likely that a few colonizing individuals, possibly even a single inseminated female, reached the island. The low initial mtDNA variability resulting from this relatively recent colonization was probably again reduced by a drastic population decline that occurred in the late 1800s because of human exploitation and introduced pests (Stoddardt et al. 1979). For a time, the population was so small that the survival of the Aldabran tortoise was uncertain, with the Governor of the Seychelles going as far as declaring extinction unavoidable (Davidson 1911). However, in 1916 the population appears to have rebounded into the thousands (Dupont 1929) and recent estimates have it around 100000 (Bourn et al. 1999). Because mtDNA is haploid and maternally inherited, the effective population size of mitochondrial genes is onequarter that of autosomal genes, so any new mutations arising since the most recent colonization would have been rare at the time of the bottleneck and could easily have been lost. Thus, a recent founder event followed by a second very recent bottleneck is a likely explanation for the invariant mtDNA genotypes observed.

\section{Acknowledgements}

Our sincerest thanks to Michel Milinkovich for providing primer sequences designed to amplify microsatellites, to Thomas Fritts for providing insights and interpretations regarding morphological differences, and to Jeremy Austin and Nicholas Arnold for helpful comments on an earlier version of the manuscript. We would also like to thank the Nature Protection Trust of Seychelles (NPTS) Silhouette, the Island Development Company (IDC) Silhouette, the Sedgwick County Zoo, the Miami Metrozoo, the Honolulu Zoo, the Phoenix Zoo, the Tulsa Zoo, the Bristol Zoo, the Detroit Zoo, the Melbourne Zoo and the Louisville Zoo for providing samples of Dipsochelys. J. Davenport (International Market Supply) provided equipment for blood sampling in the Seychelles. This work was funded through YIBS Ecosave funds to A.C.

\section{References}

Arnold EN (1979) Indian Ocean giant tortoises: Their systematics and island adaptations. Philosophical Transactions of the Royal Society of London B, 286, 127-145.

Austin JJ, Arnold EN (2001) Ancient mitochondrial DNA and morphology elucidate an extinct island radiation of Indian Ocean giant tortoises (Cylindraspis). Proceedings of the Royal Society of London B, 268, 2515-2523.

Austin JJ, Arnold EN, Bour R (2003) Was there a second adaptive radiation of giant tortoises in the Indian Ocean? Using mitochondrial DNA to investigate speciation and biogeography of Aldabrachelys (Reptilia, Testudinidae). Molecular Ecology, 12, 1415-1424.

Baker AJ, Piersma T, Rosenmeier L (1994) Unraveling the intraspecific phylogeography of knots Calidris canutus: a progress report on the search for genetic markers. Journal für Ornithologie, 135, 599-608. 
Beheregaray LB, Ciofi C, Caccone A, Gibbs J, Powell JR (2003) Genetic divergence, phylogeography and conservation units of giant tortoises from Santa Cruz and Pinzón, Galápagos islands. Conservation Genetics, 4, 31-46.

Belkhir K, Borsa P, Chikhi L, Goudet J, Bonhomme F (2000). GENETIX 4.01, Windows ${ }^{\mathrm{TM}}$ Software for Population Genetics. Laboratoire Génome, Populations, Interactions, CNRS UPR 9060, Université de Montpellier II, Montpellier, France.

Black WC, Krafsur ES (1985) A FORTRAN program for the calculation and analysis of two-locus linkage disequilibrium coefficients. Theoretical and Applied Genetics, 70, 491-496.

Bour R (1982) Contribution à la connaissance des tortues terrestres des Seychelles: définition du genre endémique et description d'une espèce nouvelle probablement originaire des îles granitiques et au bord de l'extinction. Comptes Rendus de l'Academie des Sciences Serie III, Sciences de la vie Paris, 295, 117-122.

Bour R (1984) Taxonomy, history, and geography of Seychelles land tortoises and fresh-water turtles. In: Biogeography and Ecology of the Seychelles Islands (ed. Stoddart DR), pp. 281-307. DR Dr W. Junk Publishers, The Hague.

Bour R (1994) L'etude des animaux doublement disparus; les tortues géantes subfossiles de Madagascar. Mémoires et Travaux de l'Institute de Montpellier, 19, 1-253.

Bourn D, Gibson C, Augeri D, Wilson CJ, Church J, Hay SI (1999) The rise and fall of the Aldabran tortoise population. Proceeding of the Royal Society of London B, 266, 1091-1100.

Caccone A, Gibbs JP, Ketmaier V, Suatoni E, Powell JR (1999) Origin and evolutionary relationships of giant Galápagos tortoises. Proceedings of the National Academy of Sciences of the USA, 96, 13223-13228.

Caccone A, Gentile G, Gibbs JP et al. (2002) Phylogeography and history of giant Galápagos tortoises. Evolution, 56, 2052-2066.

Ciofi C, Milinkovich MC, Gibbs JP, Caccone A, Powell JR (2002) Microsatellite analysis of genetic divergence among populations of giant Galapápagos tortoises. Molecular Ecology, 11, 2265-2283.

Cornuet J, Piry S, Luikart G, Estoup A, Solignac M (1999) New methods employing multilocus genotypes to select or exclude populations as origins of individuals. Genetics, 153, 1989-2000.

Crandall KA, Bininda-Emonds ORP, Mace GM, Wayne RK (2000) Considering evolutionary processes in conservation biology. Trends in Ecology and Evolution, 15, 290-295.

Davidson WE (1911) Land tortoises in the Seychelles. Proceedings of the Zoological Society of London, 1911, 622-624.

Dupont RP (1929) Report on a visit of investigation to the principal outlying islands of the Seychelles Archipelago. Department of Agriculture, Mahé, [typescript].

FitzSimmons NN, Moritz C, Moore SS (1995) Conservation and dynamics of microsatellite loci over 300 million years of marine turtle evolution. Molecular Biology and Evolution, 12, 432440.

Gemmell NJ, Western PS, Watson JM, Marshall-Graves JA (1996) Evolution of the mammalian mitochondrial control region sequences between monotreme and therian mammals. Molecular Biology and Evolution, 13, 798-808.

Gerlach J (1999) Distinctive neural bones in Dipsochelys giant tortoises: structural and taxonomic characters. Journal of Morphology, 240, 33-37.

Gerlach J (2003) Captive Seychelles-Aldabra giant tortoises: Reproduction, growth and dietary distortion. In: Proceedings of the International Turtle and Tortoise Symposium, Vienna, January 17-20 (eds Loehr V, Artner H), in press. Chimaira, Frankfurt/M.
Gerlach J, Canning KL (1998a) Taxonomy of Indian Ocean tortoises (Dipsochelys). Chelonian Conservation and Biology, 3, 3-19. Gerlach J, Canning KL (1998b) Identification of Seychelles giant tortoises. Linnaeus fund research report. Chelonian Conservation and Biology, 3, 133-135.

Günther ACLG (1877) The Gigantic Land-Tortoises (Living and Extinct) in the Collection of the British Museum. London, Taylor \& Francis.

Lawler SH, Sussman RW, Taylor LL (1995) Mitochondrial DNA of the Mauritian Macaques (Macaca fascicularis): an example of the founder effect. American Journal of Physical Anthropology, 96, 133-141.

MacFarland CG, Villa J, Toro B (1974) The Galapagos giant tortoises Geochelone-Elephantopus Part I Status of the surviving populations. Biological Conservation, 6, 118-133.

Mindell DP, Sorenson MD, Dimcheff DE et al. (1999) Interordinal relationships of birds and other reptiles based on whole mitochondrial genomes. Systematic Biology, 48, 138-152.

Palkovacs EP, Gerlach J, Caccone A (2002) The evolutionary origin of Indian Ocean giant tortoises. Molecular Phylogenetics and Evolution, 24, 216-227.

Palumbi S (1996) Nucleic acids II: The polymerase chain reaction. In: Molecular Systematics (eds Hillis DM, Moritz C, Manle BK), 2nd edn, pp. 205-247. Sinauer, Sunderland MA.

Penny C (1970) Cousin. In: ICBP 2nd Report to Subscribers. Unpublished Report to International Council for Bird Preservation.

Pritchard PCH (1996) The Galápagos Tortoises. Nomenclatural and Survival Status. Chelonian Research Monographs, 1, 1-85.

Pritchard JK, Stephens M, Donnelly P (2000) Inference of population structure using multilocus genotype data. Genetics, 155, 945-959.

Raymond M, Rousset F (1995a) An exact test for population differentiation. Evolution, 49, 1280-1283.

Raymond M, Rousset F (1995b) GENEPOP (Version 1.2): Population genetics software for exact tests and ecumenicism. Journal of Heredity, 86, 248-249.

Rico C, Rico I, Hewitt G (1996) 470 million years of conservation of microsatellite loci amongst fish species. Proceedings of the Royal Society of London B, 263, 549-557.

Ritland C, Ritland K (2000) DNA-fragment markers in plants. In: Molecular Methods in Ecology (ed. Baker AJ), pp. 208-234. Blackwell Science Publishers, Oxford.

Roy MS, Geffen E, Smith D, Ostrander EA, Wayne RK (1994) Patterns of differentiation and hybridization in North American wolflike canids, revealed by analysis of microsatellite loci. Molecular Biology and Evolution, 11, 553-570.

Sbisá E, Tanzariello F, Reyes A, Pesole G, Saccone C (1997) Mammalian mitochondrial d-loop region structural analysis: identification of new conserved sequences and their functional and evolutionary implications. Gene, 205, 125-140.

Stoddart DR, Peake JF, Gordon C, Burleigh R (1979) Historical records of Indian Ocean giant tortoise populations. Philosophical Transactions of the Royal Society of London B, 286, 147-158.

Taylor JD, Braithwaite CJR, Peake JF, Arnold EN (1979) Terrestrial faunas and habitats of Aldabra during the late Pleistocene. Philosophical Transactions of the Royal Society of London B, 286, 4766.

Walker D, Moler PE, Buhlmann KA, Avise JC (1998) Phylogoegraphic uniformity in mitochondrial DNA of the snapping turtle (Chelydra serpentina). Animal Conservation, 1, 55-60.

Waser PM, Strobeck C (1998) Genetic signatures of interpopulation dispersal. Trends in Ecology and Evolution, 13, 43-44. 
1412 E. P. PALKOVACS ET AL.

Weir BS, Cockerham CC (1984) Estimating F-statistics for the analysis of population structure. Evolution, 38, 1358-1370.

Wright S (1965) The interpretation of population structure by Fstatistics with special regard to systems of mating. Evolution, 19, 395-420.

Zardoya R, Vollmer DM, Craddock C et al. (1996) Evolutionary conservation of microsatellite flanking regions and their use in resolving the phylogeny of cichlid fishes (Pisces: Perciformes). Proceedings of the Royal Society of London B, 263, 1589-1598.

Zhu D, Jamieson BGM, Hugall A, Moritz C (1994) Sequence evolution and phylogenetic signal in control-region and cytochrome $\mathrm{b}$ sequences of rainbow fishes (Melanotaeniidae). Molecular Biology and Evolution, 11, 672-683.

Zug GR (1997) Galápagos tortoise nomenclature: still unresolved. Chelonian Conservation and Biology, 2, 618-619.
E.P.P. is a PhD student interested in the applications of molecular genetic techniques to questions of ecology, biogeography and conservation. M.M. performed the control region sequencing as her undergraduate thesis project. C.C. works on the genetics and ecology of endangered species of giant reptiles for in situ management and conservation plans. J.G. is investigating all aspects of the evolution of the western Indian Ocean ecosystems, with particular reference to the Seychelles islands, including ecology, phylogeny and taxonomy of vertebrate and invertebrate animals and plants. A.C. heads the YIBS - Molecular Systematics and Conservation Genetics Laboratory and works on a variety of evolutionary genetic problems including island biogeography, population genetics of mosquitoes, and conservation genetics of giant tortoises. 


\section{Appendix I}

Number of alleles analysed $(n)$ and allele frequencies for each locus and Dipsochelys morphotype

\begin{tabular}{|c|c|c|c|c|c|c|c|c|c|}
\hline \multirow{2}{*}{$\begin{array}{l}\text { Locus/morphotype } \\
\text { GAL } 50\end{array}$} & \multirow[t]{2}{*}{$n$} & \multicolumn{8}{|c|}{ Allele size (bp) and frequencies } \\
\hline & & 106 & 108 & 138 & 140 & & & & \\
\hline D. arnoldi & 14 & 0.571 & 0.071 & 0.143 & 0.214 & & & & \\
\hline D. dussumieri & 46 & 0.804 & 0.065 & 0.043 & 0.087 & & & & \\
\hline D. hololissa & 18 & 0.667 & 0.056 & 0 & 0.278 & & & & \\
\hline GAL 73 & & 84 & 86 & & & & & & \\
\hline D. arnoldi & 14 & 1 & 0 & & & & & & \\
\hline D. dussumieri & 44 & 0.932 & 0.068 & & & & & & \\
\hline D. hololissa & 18 & 0.944 & 0.056 & & & & & & \\
\hline GAL 85 & & 81 & 89 & 91 & & & & & \\
\hline D. arnoldi & 14 & 0.714 & 0.286 & 0 & & & & & \\
\hline D. dussumieri & 48 & 0.563 & 0.250 & 0.188 & & & & & \\
\hline D. hololissa & 20 & 0.750 & 0.150 & 0.100 & & & & & \\
\hline GAL 94 & & 101 & 103 & 107 & 111 & 113 & & & \\
\hline D. arnoldi & 14 & 0.071 & 0.214 & 0.357 & 0.071 & 0.286 & & & \\
\hline D. dussumieri & 38 & 0.053 & 0.211 & 0.526 & 0.105 & 0.105 & & & \\
\hline D. hololissa & 18 & 0.333 & 0.167 & 0.222 & 0.111 & 0.167 & & & \\
\hline GAL 100 & & 76 & 82 & 90 & & & & & \\
\hline D. arnoldi & 14 & 0.786 & 0.143 & 0.071 & & & & & \\
\hline D. dussumieri & 50 & 0.620 & 0.200 & 0.180 & & & & & \\
\hline D. hololissa & 20 & 0.800 & 0.150 & 0.050 & & & & & \\
\hline GAL 136 & & 85 & 87 & 89 & 109 & 139 & 141 & 159 & 163 \\
\hline D. arnoldi & 14 & 0.214 & 0.500 & 0.143 & 0.143 & 0 & 0 & 0 & 0 \\
\hline D. dussumieri & 48 & 0 & 0.708 & 0.125 & 0.104 & 0.021 & 0.021 & 0.021 & 0 \\
\hline D. hololissa & 20 & 0.100 & 0.600 & 0.100 & 0.100 & 0.050 & 0 & 0 & 0.05 \\
\hline GAL 247 & & 69 & 75 & 93 & & & & & \\
\hline D. arnoldi & 12 & 0.583 & 0 & 0.417 & & & & & \\
\hline D. dussumieri & 48 & 0.333 & 0.021 & 0.646 & & & & & \\
\hline D. hololissa & 20 & 0.250 & 0.100 & 0.650 & & & & & \\
\hline GAL 263 & & 96 & 100 & 106 & 108 & 110 & 120 & & \\
\hline D. arnoldi & 14 & 0.071 & 0.214 & 0 & 0.429 & 0.143 & 0.143 & & \\
\hline D. dussumieri & 48 & 0.146 & 0.063 & 0.042 & 0.292 & 0.292 & 0.167 & & \\
\hline D. hololissa & 20 & 0.100 & 0.050 & 0.100 & 0.650 & 0.100 & 0 & & \\
\hline
\end{tabular}

